\title{
Climate Wise Communities: Enhancing Traditional Bushfire Risk Management Using a Community Multi-Hazard Resilience Program in Sydney, Australia
}

\author{
1 Jennie Cramp, 2 Jenny Scott \\ 1 Technical Officer - Bushfire, Ku-ring-gai Council, 818 Pacific Highway Gordon \\ 2 Sustainability Program Leader, Ku-ring-gai Council, 818 Pacific Highway Gordon
}

\begin{abstract}
Recently increasing extremes in fire weather and events have highlighted deficiencies in traditional bushfire hazard management. Australian policy has yet to effectively apply social dynamics into bushfire resilience which may explain why traditional approaches fail to sufficiently protect communities. Ku-ring-gai, NSW, Australia has a history of bushfire impact due to climate, extensive urban-bushland interface and population density. To better prepare for bushfire, Ku-ring-gai Council adopted a shared responsibility approach using the Climate Wise Communities (CWC) program. Interactive exercises and scenarios facilitate assessment of extreme weather vulnerability and planning for improved resilience. In collaboration with emergency services, Government, and not-for-profit agencies Council delivered targeted workshops to highly vulnerable sectors and localities. Over 220 have participated including families, neighbourhoods, community groups and social services. Aged care and early childhood businesses also trialled a multi-hazard approach successfully. Participation guides timely evacuation, property resilience and realistic stay and defend assessments. Outcomes include better household preparedness and decision-making. Continuing program refinements will develop networks to build independence and aid recovery that will also integrate small business, property owners, women's groups and non-English speaking residents. The authors propose that social dynamics adds much needed latitude and flexibility to traditional bushfire risk management.
\end{abstract}

Keywords: Bushfire, CWC, Climate adaptation, Resilience, Shared responsibility, Preparedness, Social dynamic

\section{Introduction}

\subsection{Climate}

A comprehensive evidence base demonstrates that the global climate is changing (IPCC, 2014). The scale of the warming has often been unprecedented for millennia and the most recent decades have been some of the warmest observed on record. The risks emerging from these changed weather patterns feature more frequent and intense extreme weather events that put communities, environments and economies at risk and demand a response from decision makers into formulating actions to reduce vulnerability by strengthening preparedness.

In New South Wales, Australia the rate of the warming has accelerated in recent decades. The period of 1997-2013 was an unprecedented series of warm years with some of the hottest on record (NSW OEH, 2015). The NSW and ACT Regional Climate Modelling (NARCliM) project has generated downscaled projection models using the IPCC high emissions scenario A2 to map temperature, rainfall and Forest Fire Danger Index for twelve regional areas of South-east Australia (Evans et al., 2014). For the Sydney region maximum and minimum temperatures are 
projected to increase with more hot days (above $35^{\circ} \mathrm{C}$ ) and fewer cold nights. Rainfall variability is projected to shift seasonally, increasing in Autumn and decreasing in Spring. These projections exacerbate the fire weather risk which is expected to increase as a result, mainly during spring and summer - the typical prescribed burn periods and peak fire risk seasons (NSW OEH, 2014).

\subsection{Locality, Choices, Vulnerability}

These projections present challenges for local government areas such as Ku-ring-gai on Sydney's upper North Shore. Ku-ring-gai is a typical example of Sydney's complex topography intersecting with dense residential development. The municipality covers 8400 ha with a population of 120,978 (ABS, 2014). Past land use planning decisions have resulted in urbanised ridgetops often accessed by a single road and enveloped by extensive tall dry eucalypt forest on steep slopes. Much of this bushland is contiguous with larger natural areas in National Parks to the north, south-west and east, making it one of the most bushfire-prone areas in Greater Sydney and Australia-wide (Chen, 2005).

Despite, its bushfire-prone status, living in Ku-ring-gai is often described as a lifestyle choice. Amongst other things the areas proximity to transport, services and good schools, historic homes, sense of community and physical setting are a drawcard. Peoples choices of where to live do not necessarily acknowledge potential risk from natural hazards. This may be a result of their priorities, lack of knowledge or experience of a natural disaster or social-demographic characteristics (Solangaarachchi et al., 2012, Morrison et al., 2014, Winter and Fried, 2000 cited in Cottrell, 2005, McCaffrey et al., 2011). These elements may effect a person's risk perception which can ultimately influence their choice on where they reside (eg. the urban bushland interface) and whether they take specific precautionary actions.

\subsection{Traditional Management}

Ku-ring-gai has experienced a range of extreme weather events in the past and has a history of destructive fires impacting the urban-bushland interface. Large scale and intense bushfires impact the area on average once every 10 years (HKBFMC, 2010). To assist in reducing the risk and impact of bushfire on life, property and environment, land managers have statutory obligations and are committed to undertaking fuel management. However, recent fire events across Australia have demonstrated that traditional hazard reduction measures are inadequate in the face of large scale, catastrophic fires (VBRC, 2010). This is compounded by reduced opportunities to undertake prescribed burning and decreased effectiveness of hazard reduced areas to provide protection under extreme conditions (Lucas et al., 2007, Hennessy et al., 2005, McCarthy and Tolhurst, 2001 cited in Fernandes and Botelho, 2003).

\subsection{Consideration of a Resilience Focus}

In a national inquiry into bushfire mitigation and management following the 2002/03 fire season, Ellis, et.al (2004) concluded that we need to adapt the way we plan and respond to changed fire regimes. Although policy developments continuously demand more intensive fuel management treatments, it is evident communities remain at significant risk if they solely rely on land managers and fire agencies to protect them. The situation demands consideration of community and residential scale adaptation measures to encourage individuals to contribute to their own personal protective measures. Local governments have a duty of care under law and a moral responsibility for the welfare of their communities. Understanding this, Ku-ring-gai Council has invested in research to develop a program that assists residents to assess their vulnerability to extreme weather events and build resilience to bushfire and other natural hazards. According to the regional climate modelling such events are more likely to affect the Ku-ring-gai area in the future (NSW OEH, 2015, Taplin et al., 2010). 


\section{Features of Bush Fire Vulnerable Communities}

Fire managers are facing increasing complexities regarding the effectiveness of management decisions as our climate continues to influence erratic and challenging fire weather conditions. As a result, effective strategies for reducing exposure to loss need to be multi-dimensional (Simmons and Adams, 2004). There is increasing momentum for the facilitation of agency- community networks to strengthen resilience in communities facing extreme bushfire risks. Key objectives of the Australian National Strategy for Disaster Resilience are to foster resilient communities through partnerships and cooperative effort to improve understanding and appropriately prepare for extreme events (COAG, 2011). But how do we know what a resilient community looks like when standardised messaging focuses so heavily on properly preparing homes for the bushfire season ahead and writing a bushfire survival plan?

Resilience is a complex suite of factors that the US National Academy of Sciences defines as:

"...the ability of local communities with support from all levels of government and the private sector to plan and prepare for, absorb, respond to, and recover from disasters and adapt to new conditions". (National Research Council, 2012 p.1.)

Resilience also relies on a behavioural psychosocial element that may, for example influence an individual's capacity to choose whether to stay and defend or the way they respond to disruption and displacement (Bosomworth and Handmer, 2008, KMC, 2012). The authors of this paper contend that resilience is a combination of all these elements at personal, property and whole of neighbourhood levels (KMC, 2012).

Social research suggests that individuals who feel they belong in their community are more likely to be involved in that community and take preparation actions (Paton and Wright, 2008). Solangaarachchi et.al. (2012) found in Ku-ring-gai that community interactions help people to share their experience, knowledge and resources about bushfire. Traditionally, the community has not always had the opportunity to be a part of their own education. Message creation and delivery was the responsibility of the emergency services. These agencies typically function in a command and control manner leaving the community to assume they don't play a role (Overton, 2015). In order to share the responsibility for bushfire or other disaster preparedness, emergency management agencies need to break down the 'them' and 'us' silos by participating in trusted networks.

McLennan and Eburn (2015) consider that 'real world' wildfire management is a hybrid system in which control, choice, public values and private interests are prioritised and that there are tradeoffs between all of these. These trade-offs can be reflected in the way agencies undertake community engagement. Instead of a top-down approach, agency-community relationships can be about facilitating an understanding of bushfire or other extreme weather risks and fostering knowledge exchange to enable people to make more informed decisions regarding triggers for timely evacuation, property resilience and their capacity to stay and defend.

Following the devastating Black Saturday fires in Victoria 2009, fire managers across Australia reviewed the way they approached community engagement (VBRC 2009). In response, Akama et.al. (2012) developed a community engagement methodology, which looked at improving the way preparation messages are formulated and distributed. Their research suggested that the command and control method represented in standardised messaging was seen as disempowering by the community. In response, Akama et.al. developed a series of activities to encourage a dialogue between agencies and at risk communities. The 'design methods' developed used a combination of visual objects and 'flash' cards to assist participants to interpret and articulate collective knowledge about strengths and vulnerabilities within their neighbourhoods, define their 
social networks and heighten their awareness to emotive response in unexpected scenarios (Akama et al., 2012). These methods enable individuals to comprehend the complexities surrounding bushfire impact. Importantly such methods also reveal how informed contingency planning can play a vital role in potentially life or death scenarios.

\section{Implementing Climate Wise Communities}

In 2012, Ku-ring-gai Council, having completed a climate change adaptation strategy was considering options for implementing a community networking program to build neighbourhood capacity to prepare for and recover from extreme weather events. Ku-ring-gai Council worked with RMIT to adapt their design methods to suit the Ku-ring-gai context and implemented the Climate Wise Communities initiative (CWC).

The Climate Wise Communities program designers worked with emergency services, NGOs and other Government agencies working in the field of disaster resilience and in particular bushfire to ensure consistency with their messaging. While a gradual shift was occurring toward education of 'at risk' groups to improve resilience, most other resilience programs were still on the drawing board as CWC activities commenced. A pilot program consisting of three locality based workshops was undertaken in 2012 in areas where the bushfire technical officer assessed the risk was 'extreme' for the coming fire season. The three locations selected were very different contexts in which to test the model for its flexibility and applicability to diverse scenarios.

The first workshop was situated in a neighborhood with an active fire history. Residents had formed a community fire unit (CFU) who were well equipped and trained in defending homes in the event of a fire. This neighborhood was somewhat divided into two, those in the CFU and those who were not. The CFU members generally lived on the bushland interface while the 'others' lived in homes on the other side of the street so deemed themselves to be less at risk even though recent history had demonstrated this was not so.

The second group lived in an area that had not seen a major fire for several decades. Complacency was evident with those who attended commenting that others in their street needed to be there but would not make the time to attend. Those attending were a mix of longterm residents and others who had come more recently. Non-English speaking background people were very interested in how to communicate the risk and plan resilience to others in their cultural and linguistic groups.

The third group consisted of residents located close to a primary school and many of those who attended were parents of students in the school. These families were unaware of the level of risk of bushfire in their area and hadn't given much thought to how vulnerable their homes and lives were to this risk. Several retired residents had experienced bushfire in the area and were very concerned about how they would cope now being less physically capable in the face of a fire such as they had experienced in the past. Reviewing the pilot program assisted Council staff to better understand how to target at risk groups. Council then decided to roll out the CWC program following a bilateral strategy. The first strategy would continue to target residents in high risk locations for bushfire. The second strategy would target sectors of the community deemed 'at risk' and included aged care services, early childhood businesses, seniors living alone, cultural and linguistically diverse residents, small businesses and women particularly those with small children living at home.

Each workshop is structured according to the specific needs of each target group. Locality based workshops focus in the physical, social and to an extent the financial characteristics of the context. By using aerial photographs of the area Council staff working with the emergency 
management agencies can point out good and bad features that have influenced fire behavior in the area and how different weather characteristics could influence future fire behavior. The maps also serve to help residents better understand the logistics of evacuation with police explaining how they handle emergencies and why evacuations sometimes go wrong.

Sector based workshops also use the aerial maps to enable people to better understand how their business, clients or service might be impacted. Again with the assistance of the emergency services they can better appreciate the practicality of their emergency management plans they have in place or gather data to create or review emergency plans in the future. As workshop participants delve down to the level of their property and determine how vulnerable it is to bushfire they build a picture of the reality of their circumstances, particularly in relation to:

- How vulnerable their home is to ember attack;

- How vulnerable their home is to radiant heat;

- How defendable is their home to bushfire;

- How will they cope personally in the event of an emergency that requires physical resilience and an ability to organize and focus;

- Who can they call on for assistance if needed;

- Who might call on them for assistance;

- What are appropriate triggers for them to use to decide whether to stay or leave;

- Has their emergency management plan taken into account the full range of variables that might affect the way their plans work;

- What alternatives exist to their first option if that option is no longer open to them;

- What contingencies can be taken in advance to reduce the range of variables that could occur.

These workshops build up an appreciation of the personal circumstances of a family or business and a neighborhood. Emergency management agents explain that in the case of a large scale fire, it is likely people will be on their own to make decisions and not to expect a fire tanker to be present. As the program developed, the importance of understanding the context of the audience became increasingly relevant. For example one workshop was for a community group that had long insisted that Council or State Government needed to construct a second road as a supplementary evacuation route in the event that the main road access was cut in bushfire. This community group had received many explanations over the years to justify why a supplementary evacuation route wasn't likely to help solve any evacuation dilemmas in this location. However, the group persisted with the notion that this wasn't so. When the CWC workshop was planned for this group it was deemed a different approach again was needed.

In this workshop, the Council officers designed a 'scenario' for a possible bushfire event to 'walk' the workshop attendees through the processes occurring amongst the fire and land management agencies during a typical fire event. As each stage of this fire scenario unfolded, each agency explained what action they would be taking at that point. The community members were also asked the same question, what would you be doing at this point, under these circumstances.

The hypothetical exercise worked very well as it demonstrated that agencies were communicating effectively, their messaging was consistent and their actions precautionary. The same could not be said for the readiness, knowledge and communication between the residents. With the logistics of how events unfolded in the scenario, it became very evident to the residents that the safest option to prevent an issue from occurring around the evacuation route was for them to leave early. The lesson learned here was that if people have retrofitted their home to be more resilient to ember attack and radiant heat without the need for them being present, they are more likely to be confident in making a timely decision to leave early. 
The significance of all workshops trialed to date focused on the concepts of building trust, sharing responsibilities, and fostering conversations which are often driven by the participants themselves. Apart from learning from lived experience of bushfires, participants also started connecting with others to discuss neighborhood resilience. It is hoped connections may lead to future networks developing and help these communities become more effective in preparation and recovery in bushfire events.

\section{Conclusion}

Global warming is increasing the risk of extreme bushfire events. Despite policy developments demanding more intensive fuel management treatments as a risk abatement strategy, it is evident that communities remain at significant risk if they solely rely on land managers and fire agencies to protect them. The dependence on hazard reduction burning as the primary risk management tool has a range of unintended consequences including creating a false sense of security in vulnerable communities. The result is that communities are generally under-prepared for the current level of fire risk experienced, let alone an increase.

There is a need to balance operational bushfire risk management strategies with community oriented capacity building around the personal, property and neighborhood scale in order to increase resilience to bushfire impacts. The momentum is building for the facilitation of agencycommunity networks to foster resilient communities through partnerships and cooperative effort. New bushfire engagement methods are challenging more traditional strategies that have been based on a command and control approach that struggles to engage the community. The goal of strengthening community resilience through shared responsibility requires a more contextually specific program that can demonstrate a positive cost benefit result from household investment in resilience. The CWC program has successfully adapted a range of tools developed by RMIT University that engages localities and sectors at risk of extreme events in resilience capacity building. The CWC program aims to improve psychological preparedness and decision making capacity, allowing residents to make more informed decisions regarding strengths and weaknesses of their home and their bushfire survival plans. At the neighborhood or sector level, CWC starts conversations and strengthens networks as the facilitated activities encourage sharing of local knowledge. The next steps in this program are to analyse the potential for building more formal relationships between community networks and local emergency operators to strengthen lines of communication before, during and post extreme weather events. The authors propose that a focus on social dynamics, through programs like CWC adds much needed latitude and flexibility to traditional bushfire risk management. By developing or strengthening the social dimension, more effective outcomes should evolve for communities living with bushfire risk.

\section{References}

- ABS 2014. 3218.0 - Regional Population Growth, Australia 2013-14. Australian Bureau of Statistics. AKAMA, Y. \& CHAPLIN, S. 2013. Understanding Social Networks for Bushfire Preparation. Fire Note. Bushfire CRC and AFAC.

- AKAMA, Y., CHAPLIN, S., PHILIPS, R. \& TOH, K. Design-led strategies for bushfire preparedness. EARTH: FIRE AND RAIN Australian \& New Zealand Disaster and Emergency Management Conference, 2012 Brisbane.

- BLAIKIE, P., CANNON, T., DAVIS, I. \& WISNER, B. 2004. At Risk: Natural Hazards, People's Vulnerability and Disasters, Routlage.

- BOSOMWORTH, K. \& HANDMER, J. 2008. Climate change and community bushfire resilience In:

- HANDMER, J. \& HAYNES, K. (eds.) Community Bushfire Safety. Victoria: CSIRO Publishing. 
- CHAMP, P. A., DONOVAN, G. H. \& BARTH, C. M. 2013. Living in a tinderbox: wildfire risk perceptions and mitigating behaviours. International Journal of Wildland Fire, 22, 832-840. Crossref

- CHEN, K. 2005. Counting Bushfire-prone Addresses in the Greater Sydney Region. Sydney: Macquarie University.

- CLODE, D. 2010. A Future in Flames, Victoria, Melbourne University Press.

- COAG 2011. National Strategy for Disaster Resilience. Canberra, ACT: Council of Australian Governments.

- COTTRELL, A. 2005. Communities and bushfire hazard in Australia: More questions than answers. Global Environmental Change Part B: Environmental Hazards, 6, 109-114. Crossref

- COTTREll, A., BUSHNElL, S., SPILlMAN, M., NEWTON, J., LOWE, D. \& BALCOMBE, L. 2008. Community perceptions of bushfire risk. In: HANDMER, J. \& HAYNES, K. (eds.) Community Bushfire Safety. Collingwood, Victoria: CSIRO Publishing.

- ELLIS, S., KANOWSKI, P. \& WHELAN, R. 2004. National Inquiry on Bushfire Mitgation and Management. Commonwealth of Australia.

- ERIKSON, C. \& PRIOR, T. 2011. The art of learning:wildfire, amenity migration and local environmental knowledge. International Journal of Wildland Fire, 20, 612-624. Crossref

- EVANS, J. P., JI, F., LEE, C., SMITH, P., ARGUESO, D. \& FITA, L. 2014. Design of a regional climate modelling projection ensemble experiment - NARCliM. Geoscience Model Development, 7, 621- 629. Crossref

- FERNANDES, P. M. \& BOTELHO, H. S. 2003. A review of prescribed burning effectiveness in fire hazard reduction. International Journal of Wildland Fire, 12, 117-128. Crossref

- HENNESSY, K., LUCAS, C., NICHOLLS, N., BATHOLS, J., SUPPIAH, R. \& RICKETTS, J. 2005. Climate Change impacts on fire-weather in south-east Australia, CSIRO Australia.

- HKBFMC 2010. Hornsby/ Ku-ring-gai Bush Fire Risk Management Plan. Hornsby Ku-ring-gai Bush Fire Management Committee.

- IPCC 2014. Climate Change 2014 Synthesis Report Summary for Policy Makers.

- KMC 2012. Climate Wise Communities Pilot Project Report. Sydney: Ku-ring-gai Council.

- LUCAS, C., HENNESSY, K., MILLS, G. \& BATHOLS, J. 2007. Bushfire Weather in Southeast Australia: Recent Trends and Projected Climate Change Impacts. Consultancy Report prepared for The Climate Institute of Australia, Bushfire Cooperative Research Centre and CSIRO.

- MCCAFfREY, S. M., STIDHAM, M., TOMAN, E. \& SHINDLER, B. 2011. Outreach Programs, Peer Pressure, and Common Sense: What Motivates Homeowners to Mitigate Wildfire Risk Environmental Management, 48, 475-488. Crossref

- MCDANIEL, J. 2014. Building Trust, Establishing Credibility, and Communicating Fire Issues with the Public. Fire Science Digest. Boise, Idaho: National Interagency Fire Center.

- MCLENNAN, B. \& EBURN, M. 2015. Exposing hidden-value trade-offs: sharing wildfire management responsibility between government and citizens. International Journal of Wildland Fire, 24, 162- 169. Crossref

- MORRISON, D., LAWRENCE, C. \& OEHMEN, R. 2014. Community level influence on individual behaviours. NATIONAL RESEARCH COUNCIL 2012. Disaster Resilience: A National Imperative, Washington, DC, The National Academies Press.

- NSW OEH 2014. Metropolitan Sydney Climate change snapshot. NSW Government Office of Environment and Heritage.

- NSW OEH. 2015. AdaptNSW Observed NSW climate change [Online]. NSW Government, Office of Environment and Heritage. Available:

www.climatechange.environment.nsw.gov.au/About- climate-change-in-NSW/Evidence-ofclimate-change/Observed-NSW-climate-change [Accessed 28/07/2015 2015].

- OVERTON, K. 2015. Enhancing community response - utilising information networks during bushfires. 13th International Wildland Fire Safety Summit and 4th Human Dimensions of Wildland Fire Conference. Boise, Idaho, USA. 
Climate Wise Communities: Enhancing Traditional Bushfire Risk Management Using a Community Multi-Hazard Resilience Program in Sydney, Australia

Jennie Cramp, Jenny Scott

- PATON, D. \& WRIGHT, L. 2008. Preparing for bushfires the public education challenges facing fire agencies. In: HANDMER, J. \& HAYNES, K. (eds.) Community Bushfire Safety. Victoria: CSIRO Publishing.

- PRIOR, T. \& PATON, D. C. 2008. Understanding the Context: The value of community enagagement in bushfire risk communication and education. The Australian Journal of Disaster and Trauma, 2008-2.

- REGIONAL AUSTRALIA INSTITUTE 2013. From Disaster to Renewal: the centrality of business recovery to community resilience. Regional Australia Institute.

- SIMMONS, D. \& ADAMS, R. 2004. On the edge: how well do fire mitigation strategies work on the urban fringe? The Victorian Naturalist: Fire Symposium Special Issue, 121, 131-135.

- SMITH, K. 2013. Environmental Hazards: Assessing Risk and Reducing Disaster, New York, Routledge. Crossref

- SOlANGAARACHCHI, D., GRIFFIN, A. L. \& DOHERTY, M. D. 2012. Social vulnerability in the context of bushfire risk at the urban-bushland interface in Sydney: a case study of the Blue Mountains and Ku-ring-gai local council areas. Natural Hazards, 64, 1873-1898. Crossref

- TAPlin, R., HeNDERSON-SEllers, A., TRUECK, S., MATHEW, S., WENG, H., STREET, M., BRADFORD, W.,

- SCOTT, J., DAVIES, P. \& HAYWARD, L. 2010. Economic Evaluation of Climate Change Adaptation Strategies for Local Government: Ku-ring-gai Council Case Study, Macquarie University.

- VBRC 2010. Final Report: Summary. Victorian Bushfires Royal Commission. 